\title{
Ação Educativa a Distância: relato de uma prática com professores no Arquivo Público do Estado de São Paulo
} Education service in distance education mode: report of a practice with teachers at São Paulo State Public Archives

Andresa Cristina Oliver Barbosa* Carla Janaína Pereira de Freitas ${ }^{* *}$ Stanley Plácido da Rosa Silva ${ }^{\star * *}$

\section{Resumo}

$\mathrm{O}$ artigo tem como objetivo analisar as ações direcionadas aos professores de ciências humanas dos ensinos fundamental e médio a partir do curso " $\mathrm{O}(\mathrm{s})$ uso(s) de documentos de Arquivo na sala de aula" na modalidade EAD, oferecido pelo Núcleo de Ação Educativa do Arquivo Público do Estado de São Paulo (Apesp). Entendendo-o como uma ação pioneira em arquivos públicos do país, discutiremos inicialmente como concebemos tais instituições, bem como os pressupostos teóricos e metodológicos que embasam o curso. Após uma reflexão sobre o papel dos arquivos na sociedade e suas possíveis contribuições para a educação, analisaremos o primeiro curso em EAD oferecido ao público externo, no segundo semestre de 2013.

Palavras-chave: ação educativa em arquivos; oficinas pedagógicas; educação a distância.

\section{Abstract}

The paper aims to analyze the actions directed to teachers of humanities of elementary, middle and high schools, from the course "The use of archival documents in the classroom" delivered in distance education mode and offered by the Education Service of São Paulo State Public Archives. As we understand it as a pioneer action in public archives of the country, we will initially discuss how we conceive such institutions, as well as the theoretical and methodological assumptions that support the course. In that sense, after considering the role of archives in society and their possible contributions to education, we will analyze the first course in distance education offered to the external public, which took place in the second half of 2013. Keywords: education service in archives; pedagogical workshops; distance education.

\footnotetext{
* Diretora do Núcleo de Ação Educativa do Arquivo Público do Estado de São Paulo. andresa. oliver@hotmail.com

** Núcleo de Ação Educativa do Arquivo Público do Estado de São Paulo.car_jana@hotmail.com

*** Núcleo de Ação Educativa do Arquivo Público do Estado de São Paulo. stanleyplacido@hotmail.com
} 
Desde o ano de 2008, o Arquivo Público do Estado de São Paulo (Apesp) vem desenvolvendo sistematicamente ações de caráter educativo e cultural que objetivam a aproximação da instituição com a sociedade. Entre essas ações, destaca-se o trabalho do Núcleo de Ação Educativa (NAE), que tem como uma de suas atribuições garantir o diálogo com instituições educacionais por meio de oficinas pedagógicas para professores e alunos da educação básica e superior. Neste artigo, abordaremos a experiência do curso "O(s) uso(s) de documentos de Arquivo na sala de aula - modalidade EAD”, voltado especialmente para professores de história e demais disciplinas da área de ciências humanas da educação básica.

Realizada na modalidade presencial desde 2008 - nesse caso, para alunos de graduação -, a atividade consiste em promover o debate sobre as possibilidades de trabalho, a partir de atividades práticas e discussões metodológicas sobre o uso de fontes documentais em sala de aula. No caso da modalidade de ensino a distância (EAD), essa experiência vem sendo realizada desde 2013, contando com a sua $3^{\text {a }}$ edição ( $1^{\circ}$ semestre de 2014$)$, a primeira das quais foi um piloto realizado com os servidores do Apesp.

A proposta de oferecer cursos para professores por meio do EAD tem como objetivo fortalecer ações que convirjam para a democratização da instituição e do acesso aos documentos sob sua guarda. Outro aspecto importante é o alcance da ferramenta tecnológica do EAD, que possibilita que os cursos oferecidos pelo Apesp cheguem não somente ao público da cidade de São Paulo, mas ao interior do estado e também a outras regiões do Brasil.

\section{ARquiVo E SUA RELAÇÃo COM A SOCIEDADE: UM BREVE HISTÓRICO ${ }^{1}$}

Podemos entender o processo de aproximação entre Arquivo $^{2}$ e sociedade a partir de dois marcos que influenciaram diretamente o conceito de Arquivo: a Revolução Francesa (1789) e a Segunda Guerra Mundial (1939-1945). O primeiro propiciou a abertura dos Arquivos para um público preocupado com a construção de uma história nacional, e o segundo pautou-se por garantir os direitos individuais e coletivos - entre eles o direito à informação, dando aos Arquivos um novo status. Ambos os casos reforçaram a ideia de que as instituições arquivísticas precisam ir além do servir exclusivamente ao Estado ou à sua administração. 
No Brasil, a pauta do direito à informação só se tornou formulação legal na Constituição Federal Brasileira de $1988,{ }^{3}$ com a mobilização da sociedade na luta pela redemocratização do país e pelo "direito a ter direito" (Paoli, 1989).

Nesse sentido, a abertura dos Arquivos é forjada em meio às transformações políticas do país, marcadas pela reivindicação da sociedade pelo fim do regime ditatorial e pelo restabelecimento da democracia, cujos objetivos nortearam os ideais para a constituição da nação e das leis que a regem. Conjuntamente a essa luta, o direito à informação e ao passado é proposto enquanto dimensão básica da cidadania, exigindo o desenvolvimento de estratégias para a extroversão dos Arquivos.

Assim, os direitos à informação e à memória passam a ser garantidos por meio dos incisos XIX e XXXIII do Artigo $5^{\circ}$, Título II, Capítulo I, que trata Dos Direitos e Deveres Individuais e Coletivos:

XIV - É assegurado a todos o acesso à informação e resguardado o sigilo da fonte, quando necessário ao exercício profissional;

$\cdots$

XXXIII - Todos têm direito de receber dos órgãos públicos informações de seu interesse particular, ou de interesse coletivo ou geral, que serão prestadas no prazo da lei, sob pena de responsabilidade, ressalvadas aquelas cujo sigilo seja imprescindível à segurança da sociedade e do Estado.

Já no $\$ 2$ do Artigo 216, Capítulo III, referente às questões ligadas à educação, à cultura e ao desporto, preconiza-se a responsabilidade da administração pública na gestão da documentação governamental e nas providências para franquear sua consulta a todos os cidadãos. A inclusão desse parágrafo foi fundamental na época, tendo em vista que até aquele momento não existiam leis específicas sobre a política nacional de Arquivos que garantissem a disponibilização e o acesso aos documentos produzidos pelas diversas administrações públicas.

É importante indicar que, com a criação da Lei de Arquivos em 1991 (Brasil, Lei 8.159), as instituições arquivísticas ganharam maior legitimidade quanto ao seu papel cultural junto à sociedade - ao menos é o que propõe a Lei. Os acervos sob guarda dos Arquivos passam a ser entendidos tanto como instrumentos de apoio para o desenvolvimento da cultura quanto para servir à administração, às questões científicas e aos fins comprobatórios. 
No campo teórico e legal, as ações educativas e de difusão nos Arquivos estão plenamente justificadas e asseguradas. No entanto, no campo da gestão de recursos e nas práticas de Arquivo, o investimento em ações desse tipo ainda tem um caminho longo para trilhar. Grande parte dos Arquivos públicos enfrenta questões de falta de recursos, instalações precárias e invisibilidade frente aos dirigentes. Compreendendo a conjuntura precária vivida pela maioria, somada à priorização - mesmo entre as instituições de melhor condição - das ações de tratamento documental dos arquivos permanentes, pouco sobra para investir em programas e projetos que envolvam a aproximação da sociedade e da escola - em particular - ao patrimônio documental.

Embora reconhecida a importância das atividades de difusão educativa e cultural nas instituições arquivísticas, elas ainda são tratadas como ações secundárias em relação à função principal dos Arquivos. Bellotto (2007, p.227) afirma que os Arquivos públicos existem primordialmente para recolher, custodiar, preservar e organizar documentos produzidos pelo governo, e que as ações de difusão (editorial, cultural e educativa), embora secundárias, é que fomentam os contornos sociais da instituição. Porém, compreendemos que as ações de difusão cultural e educativa nos Arquivos devem ocupar um lugar entre as suas atividades primordiais:

É por meio da difusão que é dada visibilidade às fontes, antecipando ao público a riqueza documental de um Arquivo. Sua importância está em chamar a atenção para o que está guardado, em dar publicidade ao que já é público, mas que muitos não conhecem; em construir, através do conhecimento desse patrimônio, a noção do seu valor. (Barbosa; Silva, 2012)

Quando tratamos dos Arquivos como campo em potencial para a educação - desprendendo-nos da visão clássica de que seriam instituições voltadas exclusivamente para o serviço da investigação científica e da administração pública -, percebemos que eles ainda ocupam um tímido espaço dentro das discussões e das práticas arquivísticas no Brasil. Em países como França, Inglaterra e Irlanda, essa concepção - Arquivo e educação - é discutida desde a década de 1950, quando foi tema da primeira conferência internacional da “Table Ronde des Archives”, em 1954. Naquele momento, entendia-se por "Serviço Educativo" as atividades voltadas predominantemente ao atendimento do público escolar e, em menor escala, aos demais cidadãos. Sendo assim, 
El Servicio Educativo nace con el objetivo fundamentalmente pedagógico, con la finalidad de ofrecer a los alumnos de enseñanza primaria y secundaria un contacto directo con los documentos. Por otra parte, su implantacion se ve beneficiada por la evolución de los métodos pedagógicos que intentan potenciar la observación y la experimentación del alumno, contrariamente de la clásica enseñanza empeñada en convertir al estudiante en un mero receptor pasivo de conocimientos, y también por el formidable desarollo experimentado por la historia local. (Alberch; Boadas, 1991, p.94)

A partir de então, a abertura dos Arquivos aos públicos escolares ganhou destaque nas políticas institucionais, como foi o caso da França. Em 1950, foi criado o primeiro "Serviço Educativo" nos Archives Nacionales, tendo como referência as práticas já existentes em museus. Em 30 anos, esse tipo de atividade difundiu-se por toda a França, alcançando ótimos resultados.

Se, no âmbito internacional, a relação entre Arquivo e educação é consequência de uma realidade originada no pós-guerra, no Brasil, o reconhecimento do papel educacional e pedagógico das instituições arquivísticas é bem recente. Localizadas a partir do final da década de 1980, as discussões referentes às reformas curriculares empreendidas em âmbito nacional - gestadas em meio à conjuntura da redemocratização brasileira - potencializaram a ideia de os Arquivos dialogarem com a educação. Outro fator que vem contribuindo para o fortalecimento dessa concepção é a aproximação dos Arquivos com as discussões acerca da educação para o patrimônio, disseminadas nas instituições museológicas.

Diferentemente de uma biblioteca, que é um órgão colecionador que reúne artificialmente suas unidades pelo seu conteúdo (assunto), os Arquivos públicos são instituições custeadoras de documentos originais produzidos pela administração pública e sua organização é norteada segundo sua origem e função, ou seja, a lógica da pesquisa é um processo mais complexo, tornando-se uma tarefa, muitas vezes, árdua. Várias questões podem ser trabalhadas a partir dessa constatação. Uma delas é a necessidade de se iniciar uma discussão acerca da produção de instrumentos de acesso e pesquisa, como guias de acervo, inventários e catálogos mais democráticos e que dialoguem com toda a sociedade.

Ao contrário das bibliotecas ou, até mesmo, dos museus, o acervo de um arquivo, pela sua natureza e por seu grande volume, é arranjado de acordo com o 
princípio da proveniência, que busca valorizar, em primeiro lugar, a memória da lógica administrativa da produção dos documentos. Assim, pela própria natureza da documentação arquivística e da forma como é organizada, os estudantes convivem com algumas dificuldades para acessar a informação, que não se classifica por assunto, modo de consulta a que estão acostumados. (Ribeiro; Santos; Hermeto, 2010)

Eis aqui um dos desafios do trabalho de difusão cultural e educativa: transformar a documentação histórica dos Arquivos em produtos que dialoguem com o público escolar e a sociedade em geral, de forma a promover a sua ampla democratização. Assim, conceber as instituições arquivísticas como espaços que vão além da guarda de documentos para servir à administração, aos fins comprobatórios e ao uso da academia é um dos desafios colocados aos Arquivos desde o final do século XX.

Nesse sentido, o Núcleo de Ação Educativa (NAE) do Apesp tem como função precípua promover a interlocução entre o Arquivo e a sociedade em geral, com foco nos graduandos e nos alunos e professores da educação básica. Por meio de cursos, oficinas, palestras, exposições e outras atividades variadas, busca difundir o acervo e o nome da instituição para esses setores da sociedade, conforme define o Decreto Estadual no 54.276 de 2009:

Artigo 20 - O Centro de Difusão e Apoio à Pesquisa tem as seguintes atribuições:

III - por meio do Núcleo de Ação Educativa:

a) elaborar programas de ação educativa com vista a aproximar a Unidade do Arquivo Público do Estado de instituições educacionais e da sociedade em geral;

b) desenvolver materiais de apoio pedagógico a partir de documentos do acervo;

c) promover oficinas de qualificação de professores e de outros profissionais da memória;

d) proporcionar visitas monitoradas a estudantes e a professores de instituições de ensino. (grifos nossos)

A experiência que relatamos neste artigo converge, assim, com as atribuições do NAE elencadas no referido decreto e reforça, de forma prática, o elo entre Arquivo e educação. 


\section{Pressupostos teórico-Metodológicos Do CURSO}

Por meio de discussões metodológicas e atividades práticas de análise de documentos, procuramos estabelecer um espaço de elaboração didática conjunta com os professores-alunos do curso. A prática didática, nesse caso, pode ser compreendida de duas maneiras. A primeira, considerando-se o sentido mais amplo da didática, refere-se às relações estabelecidas entre Arquivo, sociedade, memória e educação, que se espera consolidar no espaço escolar, levando o patrimônio documental e as questões que o envolvem a extrapolar os limites do espaço institucional arquivístico.

O segundo aspecto essencial da prática didática da oficina parte da premissa de que o conhecimento histórico e o conhecimento próprio das demais disciplinas das ciências humanas são produzidos no espaço escolar, e não apenas reproduzidos nele. A partir desse entendimento, o professor não é visto como mero caudatário das pesquisas e produções acadêmicas, e os alunos como receptores passivos de conhecimento. Ao contrário, ambos são compreendidos como partícipes da produção do saber. ${ }^{4}$

Ao mesmo tempo, compreende-se que o conhecimento acadêmico e a esfera escolar da produção do saber histórico dialogam, ainda que de maneira desigual. Sendo assim, o conteúdo da oficina é composto tanto por discussões teóricas acerca dos objetos, problemáticas e metodologias próprias da disciplina quanto por elaborações sobre a prática didática dela.

O centro de nossa abordagem é a utilização de documentos de Arquivo na educação básica, conforme deixa claro o próprio título do curso. Esse não é um tema novo, já que desde as primeiras décadas do século XX verifica-se a utilização de documentos em livros didáticos. Contudo, nesse período, os documentos eram utilizados majoritariamente para ilustrar o texto; não havia preocupação em contextualizá-los ou abordar o processo de sua produção, pois serviam apenas para confirmar o conteúdo ensinado (Caimi, 2008). Recentemente, as políticas educacionais apontam em outro sentido e redefinem o papel a ser desempenhado pelas fontes documentais no espaço escolar. O documento passa a ser objeto de problematizações e estudos que visam apreender o seu processo de produção, as suas relações com a sociedade produtora e os indícios de situações que, a partir deles, podem ser interpretadas. 
A pesquisa adquire uma dimensão essencial no processo de aprendizagem da história, pois, ao compreender certos aspectos de sua produção, o aluno assume um papel ativo na construção do conhecimento histórico. Não se trata, é claro, de almejar que o estudante domine todo o arcabouço do fazer historiográfico, mas permitir que ele identifique as marcas de produção da narrativa, suas relações com o presente e as metodologias próprias de sua elaboração. ${ }^{5}$

Tais diretrizes sobre a utilização de documentos em sala de aula podem ser observadas em diferentes instrumentos orientadores de políticas educacionais para o ensino fundamental e médio, como nos Parâmetros Curriculares Nacionais (PCNs) e na matriz de referência do Exame Nacional do Ensino Médio (Enem), por exemplo. Nessa última, na área das ciências humanas e suas tecnologias, verificamos as seguintes habilidades desejadas:

Competência de área 1 - Compreender os elementos culturais que constituem as identidades.

H1 - Interpretar historicamente e/ou geograficamente fontes documentais acerca de aspectos da cultura.

H2 - Analisar a produção da memória pelas sociedades humanas.

H3 - Associar as manifestações culturais do presente aos seus processos históricos.

H4 - Comparar pontos de vista expressos em diferentes fontes sobre determinado aspecto da cultura.

H5 - Identificar as manifestações ou representações da diversidade do patrimônio cultural e artístico em diferentes sociedades. (Brasil/MEC, Edital n ${ }^{\circ} 1$, 2013)

Sendo assim, por meio do documento, o aluno pode, com a mediação do professor, questionar, confrontar informações divergentes, interpretar detalhes e, principalmente, refletir e elaborar sínteses sobre problemáticas históricas. Vislumbra-se, dessa maneira, a possibilidade de promover a desnaturalização da memória e da identidade, apresentando condições de uma apropriação consciente delas por parte dos estudantes.

Essas transformações na concepção do ensino de história, entre outras, ocorreram de forma imbricada, porém não de maneira subordinada, com as mudanças na própria compreensão da história. Nas primeiras décadas do século XX, o surgimento da Escola dos Annales, na França, impulsionou novas abordagens para o campo da história e fomentou a ampliação da noção de 
documento, que deixa de ser apenas o papel escrito e passa a abranger outras possibilidades. A grande mudança na concepção de história a partir dessa corrente historiográfica foi a primazia da história-problema. Também se altera o tratamento dado ao documento e a sua crítica. Ele passa a ser definido pelas interrogações da pesquisa e, para além da determinação de sua autenticidade - que exerceu grande importância até o século XIX -, interessava aos fundadores dos Annales uma crítica em profundidade da noção de documento.

O documento não era mais um vestígio, mas sim um produto do passado, mais especificamente, produto de uma cultura. Assim, a análise de documentos passa a considerar a história como um discurso em litígio, uma disputa pela hegemonia entre grupos de interesses divergentes. Por isso, para Le Goff (2003), todo documento deve ser criticado enquanto monumento, pois não existe um documento neutro. As condições históricas de sua produção tornam-se essenciais para compreendê-lo e para apreender a representação que as sociedades históricas desejaram imprimir de si próprias nos documentos.

Assim, partindo das discussões do campo teórico e didático da história acima expostos, o curso foi organizado em seis unidades temáticas, acrescidas de uma unidade específica para a elaboração do trabalho final. Cada uma delas contou com atividades avaliativas compostas por questões objetivas ou dissertativas acerca da bibliografia proposta. O curso contou também com o fórum avaliativo "Arquivo, Patrimônio e Ensino", no qual foram desenvolvidos debates em torno dos temas anunciados no seu título.

Foram realizados dois encontros presenciais, totalizando 10 horas. O primeiro contemplou uma visita monitorada às dependências do Apesp, orientações sobre o uso da plataforma Moodle e esclarecimentos sobre os instrumentos avaliativos do curso e respostas a dúvidas específicas dos participantes. $\mathrm{O}$ último encontro presencial concentrou-se na apresentação dos trabalhos finais.

Nas três primeiras unidades da oficina tecemos discussões em conjunto com os professores-alunos sobre conceitos como história, patrimônio, documento e educação. Elas ocorreram a partir da leitura de bibliografia indicada, de textos de apoio e da visualização de vídeos, e se concretizaram, principalmente, por meio do fórum.

Nas três unidades subsequentes, priorizamos as atividades prático-metodológicas de análise de documentos. Optamos pela divisão dessas unidades em função da especificidade dos documentos a serem abordados, organizando-os 
em iconográficos e cartográficos, textuais e periódicos devido às particularidades que cada um deles apresenta. Há ainda nessas unidades a leitura obrigatória de bibliografia específica; contudo, o centro da proposta não é o debate teórico das ideias e conceitos abordados neles, mas sim a elaboração de um roteiro de análise de cada um dos tipos documentais apontados acima, voltados para a educação básica. Pretendia-se, com tais unidades, que o professor-aluno se familiarizasse com a metodologia própria de análise de diferentes tipos documentais, inseridos na concepção mais geral acerca da necessidade de problematizar os documentos como monumentos.

Além das atividades e unidades descritas até aqui, faz parte do processo formativo da oficina e constitui elemento fundamental para a aprovação dos participantes a elaboração de uma sequência didática como trabalho final. Ela deve ser feita individualmente e contemplar necessariamente propostas de análise de documentos de arquivo. ${ }^{6}$

Como observa Rocha (2009), os avanços metodológicos conquistados pelo ensino de história nas últimas décadas, inclusive no que tange à utilização de documentos como alternativa à exposição do professor no acesso ao conhecimento histórico escolar, são importantes. No entanto, não devemos perder de vista a preocupação com a estruturação da aula, para que as novas práticas metodológicas não sejam aplicadas de maneira isolada. Nesse sentido, a autora destaca as atividades permanentes, os projetos e as sequências didáticas como diferentes propostas de organização de unidades de ensino, considerando a integração dos conteúdos e objetivos ao longo das aulas.

Optamos pela sequência didática como trabalho final da oficina por ela envolver necessariamente a organização de propostas didáticas articuladas e promover uma continuidade entre elas. Além disso, vislumbramos nessa forma de organização de conteúdos específicos a possibilidade de contemplar com coerência a utilização de diversificadas fontes em torno de objetivos determinados. Nessa proposta, a sequência didática deverá partir de um "problema”, ou seja, deve problematizar situações com o intuito de demonstrar a historicidade das interpretações, além de estabelecer relações entre a sociedade do presente e o passado.

A partir de um roteiro para elaboração de sequência didática, desenvolvido pela equipe do NAE, os participantes realizam o trabalho final com temas abertos, de livre escolha. Os documentos que deverão compor 
parte das atividades didáticas podem ser consultados em variadas instituições arquivísticas, como os arquivos da região de atuação do professor. Caso o participante encontre dificuldades para ter acesso aos acervos locais, poderá utilizar os "kits pedagógicos" disponibilizados no Ambiente Virtual de Aprendizagem (AVA), que consistem em coleções de reproduções digitais de documentos do acervo Apesp. Esses kits estão organizados em torno de cinco temáticas, a saber, Anistia, Criminalidade, Imigração, Propaganda e Rio Tietê, e são formados por diferentes tipos documentais.

Considerando que a proposta de realização de um trabalho final não tem função meramente avaliativa, mas principalmente formativa, os professores-tutores do curso acompanham as diversas etapas de elaboração das sequências didáticas e enviam devolutivas sobre o andamento dos trabalhos de cada aluno, ao menos em três momentos diferentes antes da finalização destes. Esse processo culmina na apresentação das sequências didáticas pelos participantes durante o último encontro presencial do curso.

Mais do que avaliar as habilidades oratórias dos alunos, o que desejávamos e pudemos presenciar foi o compartilhamento de experiências em torno da documentação utilizada, dos caminhos escolhidos e percorridos, das opções que foram abandonadas, enfim, das soluções encontradas na elaboração das sequências didáticas e dos resultados alcançados por cada um.

\section{RELATANDO A PRIMEIRA EXPERIÊNCIA}

O curso na modalidade Ensino a Distância (EAD) demandou do NAE um considerável tempo em sua preparação e na capacitação de sua equipe. Primeiramente, tratou-se de realizar cursos de diversas temáticas no sentido de "experimentar" os formatos variados de cursos livres que se aproximassem do formato de nossa proposta. A partir dessa experiência, analisamos quais estratégias seriam factíveis, levando-se em consideração a carga horária, a temática e o público-alvo esboçados para essa primeira experiência do Apesp.

Em um segundo momento, tratamos de nos capacitar para, de fato, ofertar o curso. Depois de alguns cursos sobre como utilizar o AVA (Ambiente Virtual de Aprendizagem), trabalhamos na adaptação do curso oferecido no formato presencial às especificidades inerentes à modalidade EAD. Pela sua praticidade 
e viabilidade, a escolha recaiu sobre a Plataforma Moodle, amplamente utilizada pelas universidades públicas do país.

Assim, antes de ofertá-lo ao público externo, foi realizado um curso-piloto com funcionários e estagiários do Apesp no primeiro semestre de 2013, com o objetivo de verificar a confiabilidade/usabilidade do Moodle e as questões pedagógicas mais gerais, como carga de leitura, tempo de realização do curso e tempo para realização das tarefas, entre outros aspectos. ${ }^{7} \mathrm{O}$ curso-piloto teve início com 21 participantes, oriundos de diversas áreas acadêmicas como história, filosofia, letras, geografia, pedagogia, psicologia e biblioteconomia, entre outras. Destes, nove concluíram o curso e fizeram sugestões a partir de um questionário avaliativo.

Com base nesse piloto, algumas alterações e adequações foram realizadas para melhor compatibilizar o conteúdo do curso às possibilidades de interação e estratégias de aprendizagem que o AVA permite, já que estamos tratando de propiciar a interação dos participantes; ampliar o acesso a informações continuamente atualizadas; favorecer a mediação pedagógica em processos síncronos ou assíncronos; e criar espaços para representação do pensamento e produção de conhecimento (Almeida, 2005).

Nesse sentido, destacam-se as seguintes modificações: ampliou-se o tempo de duração de cada uma das seis unidades do curso de 7 para 10 dias, reduziu-se de duas para apenas uma a quantidade de fóruns avaliativos, ampliou-se a carga total de 40 para 50 horas, foi incluída a temática cartográfica no curso, outrora inexistente, e houve a instalação de um fórum não avaliativo específico para o esclarecimento de dúvidas em relação ao trabalho final.

Entre $1^{\circ}$ de setembro e 10 de novembro de 2013, foi realizado o primeiro curso "O(s) uso(s) de documentos de Arquivo na sala de aula" na modalidade EAD. Depois de uma divulgação realizada por meio de banners no site do Apesp, da Escola de Formação e Aperfeiçoamento de Professores Paulo Renato Costa Souza da Secretaria Estadual de Educação (EFAP/SEE) e da Secretaria de Educação do Estado de São Paulo, complementados pelo envio de e-mails a diversas instituições de ensino superior, ensino básico, pesquisadores e interessados no trabalho desenvolvido pelo NAE, foram recebidas 1.524 inscrições para um total de oitenta vagas.

O público-alvo era de graduados em história ou nas demais áreas das ciências humanas que estivessem em efetivo exercício nas redes públicas ou 
particular de ensino, nas disciplinas de sua formação ou em áreas correlatas. Também poderiam se inscrever profissionais ligados a Arquivos, museus e congêneres. Dos 1.524 inscritos, 1.109 eram profissionais de escolas públicas estaduais, ${ }^{8} 158$ de públicas federais ou municipais, 88 de particulares e 72 de instituições arquivísticas, museológicas ou afins. Algumas das inscrições (97) não se encaixavam no perfil do público-alvo, as quais foram classificadas como "Outros".

A quantidade de inscritos foi 19,05 vezes superior ao número de vagas ofertadas (80). ${ }^{9}$ Em vista disso, foram acionados cuidadosamente os critérios de seleção publicados no edital: número de inscrições para cada rede de ensino; prioridade para os que residiam fora da capital paulista; maior tempo de formação e, por fim, a idade. Dessa maneira, acrescidos três participantes à parte do processo seletivo realizado, ${ }^{10}$ o curso teve início com 83 matriculados divididos entre professores da rede pública estadual (41), rede pública federal e municipal (23), rede particular de ensino (11) e profissionais de Arquivos, museus e afins (8).

No que se refere ao perfil geográfico dos inscritos, estes eram provenientes de 283 municípios diferentes, com a esperada predominância das cidades paulistas com maior número de habitantes, como se pode observar na Tabela 1. Conforme anunciado no edital de abertura de inscrições, o critério geográfico era preponderante na seleção dos candidatos.

Tabela 1 - Quantidade de inscritos - 20 municípios com maior número de inscritos

\begin{tabular}{l|lc|l|c|c}
\hline \multicolumn{1}{c|}{ Município } & UF & Inscritos & \multicolumn{1}{c}{ Município } & UF & Inscritos \\
\hline São Paulo & SP & 430 & Ribeirão Preto & SP & 18 \\
Guarulhos & SP & 67 & Mogi das Cruzes & SP & 16 \\
Campinas & SP & 34 & Taubaté & SP & 16 \\
Osasco & SP & 31 & Franca & SP & 15 \\
São José dos Campos & SP & 28 & Mauá & SP & 14 \\
São Bernardo do Campo & SP & 24 & Suzano & SP & 14 \\
Sorocaba & SP & 24 & Taboão da Serra & SP & 13 \\
Bauru & SP & 21 & Piracicaba & SP & 12 \\
Santo André & SP & 21 & Rio Claro & SP & 12 \\
Limeira & SP & 19 & Rio de Janeiro & RJ & 12 \\
\hline
\end{tabular}

Fonte: Apesp, 2013. 
Diante da enorme procura verificada, a preferência recaiu sobre os 1.094 inscritos não residentes na capital paulista, e nenhum dos 430 inscritos da cidade foi matriculado. Do total de inscritos, 121 se declararam residentes em outros estados. Assim, o curso selecionou candidatos de 59 municípios diferentes, dos quais sete candidatos de cinco municípios fora de São Paulo.

Em relação à formação acadêmica, a maioria dos inscritos declarou ser da área de história. No entanto, os profissionais de pedagogia, geografia, ciências sociais, letras e filosofia também compuseram de forma significativa o número de inscritos. Candidatos que não especificaram a formação, assim como aqueles que não se enquadravam no público-alvo (Outros), compuseram o restante dos inscritos.

Tabela 2 - Perfil inscritos x matriculados por área de formação

\begin{tabular}{lcccc}
\hline \multicolumn{1}{c}{ Área de Formação } & Inscritos & $\%$ & Matriculados & $\%$ \\
\cline { 1 - 2 } História & 976 & 64,04 & 59 & 71,10 \\
Pedagogia & 128 & 8,40 & 4 & 4,82 \\
Geografia & 110 & 7,22 & 5 & 6,02 \\
Outros * & 88 & 5,77 & 5 & 6,02 \\
Ciências Sociais & 76 & 4,99 & 3 & 3,61 \\
Letras & 75 & 4,92 & 3 & 3,61 \\
Filosofia & 46 & 3,02 & 4 & 4,82 \\
Não especificado & 25 & 1,64 & 0 & 0,00 \\
Total & 1.524 & 100,00 & 83 & 100,00 \\
\hline
\end{tabular}

Fonte: Apesp, 2013.

* Nesta categoria ficaram tanto os profissionais de áreas conexas, como artes, biblioteconomia e arquivologia, que suscitam a possibilidade de serem incluídos no rol de inscrições diretas, como profissionais de áreas bem distintas do público-alvo do curso, tais como educação física, ciências biológicas e comunicação social.

A predominância da área de história - tanto entre os inscritos como entre os matriculados - era algo previsto, haja vista as unidades temáticas do curso e a própria relação do Arquivo Público com profissionais desse perfil. Todavia, ter mais de $30 \%$ de inscritos que se declararam de outras áreas é observado, de 
maneira geral, como algo positivo, pois significa, em nossa percepção, que o Apesp é cada vez mais "Público" e não apenas "Histórico".

No que concerne ao tempo de graduação dos candidatos, isto é, há quanto tempo são graduados nas respectivas áreas de atuação, considerando-se a indicada pelos candidatos no ato da inscrição, ${ }^{11}$ obtivemos um grande número de inscritos com formação da década de 1990 em diante, com destaque para a década de 2001-2010, o que demonstra que mesmo os graduados com formação recente continuam buscando algum tipo de formação continuada.

Tabela 3 - Perfil inscritos x matriculados por ano de graduação

\begin{tabular}{lcccc}
\hline \multicolumn{1}{c}{ Ano de graduação } & Inscritos & $\%$ & Matriculados & $\%$ \\
\hline 1961-1970 & 3 & 0,2 & 1 & 1,2 \\
$1971-1980$ & 8 & 0,54 & 0 & 0 \\
$1981-1990$ & 118 & 7,96 & 26 & 30,12 \\
$1991-2000$ & 332 & 22,39 & 34 & 42,17 \\
$2001-2010$ & 717 & 48,35 & 22 & 26,51 \\
$2011-2013$ & 305 & 20,56 & 0 & 0 \\
\hline Total & $1.483^{*}$ & 100 & 83 & 100 \\
\hline
\end{tabular}

Fonte: Apesp, 2013.

* Foram desconsiderados 41 candidatos que não preencheram o formulário de inscrição corretamente.

Como indicado na Tabela, o peso atribuído ao ano de conclusão do curso de graduação como critério de seleção levou os candidatos mais jovens na carreira a obterem um quantitativo proporcionalmente menor de vagas em relação ao percentual de inscritos. Não obstante, analisando as Tabelas 2 e 3, podemos afirmar que não houve grandes distorções entre o percentual de inscritos e o de matriculados nos quesitos "tempo de graduação" e "área de formação", o que indica que os critérios de seleção, grosso modo, contemplam de forma satisfatória a demanda pelas vagas do curso.

Entre os 83 matriculados no curso, 43 cumpriram as exigências acadêmicas e de frequência, e concluíram-no com êxito. ${ }^{12}$ Solicitou-se aos concluintes que avaliassem o curso a partir de um questionário objetivo que, em seus últimos tópicos, abria a possibilidade de o cursista apontar os pontos fortes e eventuais oportunidades de melhoria para a oficina. A avaliação não 
era obrigatória e, dos 43, 38 concordaram em fazê-la. No primeiro item, “Aspectos gerais do curso" - que abarcou as questões não pedagógicas do curso (ver Tabela 4) -, apenas a divulgação obteve índice de satisfação - Bom ou Excelente - inferior a $80 \%$, com os demais itens superando facilmente esse percentual.

Tendo isso em vista, de forma a melhorar esse aspecto nas edições seguintes, atualizamos o nosso mailing, apresentamos o projeto com mais antecedência à EFAP/SEE-SP e obtivemos a homologação do curso pela Secretaria $\mathrm{Mu}$ nicipal de Educação de São Paulo (SME/SP), de modo que ele fosse publicado também no Diário Oficial da Cidade de São Paulo. Ampliamos assim a divulgação no âmbito da capital paulista e introduzimos um elemento motivador para que esses professores também buscassem nosso curso como uma opção de formação continuada, visto que, depois dessa edição, os candidatos da capital também passaram a ter um percentual mínimo de vagas para matrícula. ${ }^{13}$

Tabela 4 - Aspectos Gerais do Curso (\%)

\begin{tabular}{lcccc}
\hline \multicolumn{1}{c}{ Item Analisado } & Excelente & Bom & Regular & Ruim \\
\hline Divulgação & 45 & 34 & 21 & 0 \\
Inscrição & 68 & 29 & 3 & 0 \\
Critérios de seleção & 53 & 44 & 3 & 0 \\
Carga horária & 42 & 47 & 11 & 0 \\
Instalações & 97 & 3 & 0 & 0 \\
Material de apoio & 89 & 11 & 0 & 0 \\
Periodicidade das avaliações & 41 & 46 & 13 & 0 \\
\hline
\end{tabular}

Fonte: Apesp, 2013.

Os cursistas avaliaram também o AVA. Três aspectos, referentes à ambientação, à organização e à facilidade de uso foram avaliados, e nenhum deles obteve percentual inferior a 90\% de aprovação, mesmo com a informação transmitida nos encontros presenciais de que muitos professores-alunos estavam realizando um curso a distância pela primeira vez, como pode ser observado na Tabela 5 . 
Tabela 5 - Ambiente Virtual de Aprendizagem (\%)

\begin{tabular}{lcccc}
\hline \multicolumn{1}{c}{ Item Analisado } & Excelente & Bom & Regular & Ruim \\
\hline Ambientação ao AVA & 66 & 29 & 5 & 0 \\
$\begin{array}{l}\text { Organização das informações } \\
\text { e atividades }\end{array}$ & 68 & 29 & 3 & 0 \\
Facilidade de utilização & 45 & 45 & 10 & 0 \\
\hline
\end{tabular}

Fonte: Apesp, 2013.

O terceiro ponto avaliado esteve relacionado ao que denominamos "Aspectos pedagógicos gerais", onde questões como a temática e a pertinência do curso, assim como a atuação dos professores e do monitor ${ }^{14}$ foram avaliados. Os resultados foram excelentes, visto que nenhum dos itens obteve a menção "Regular" e, mais que isso, tanto a temática do curso como a atuação dos professores obtiveram $97 \%$ de "Excelente", cabendo mencionar que a atuação do monitor também obteve ótima avaliação, com 95\% dos cursistas considerando sua atuação excelente.

Tabela 6 - Aspectos Pedagógicos Gerais do Curso (\%)

\begin{tabular}{lccccc}
\hline \multicolumn{1}{c}{ Item Analisado } & Excelente & Bom & Regular & Ruim \\
\hline Temática / Proposta do curso & 97 & 3 & 0 & 0 \\
Adequação aos objetivos do curso & 92 & 8 & 0 & 0 \\
Grau de profundidade do curso & 79 & 21 & 0 & 0 \\
Atuação dos Professores & 97 & 3 & 0 & 0 \\
Critérios de Avaliação & 68 & 32 & 0 & 0 \\
Atuação do Monitor & 95 & 5 & 0 & 0 \\
\hline
\end{tabular}

Fonte: Apesp, 2013.

Aspecto importante de nossa oficina, a exigência de uma sequência didática como trabalho final também foi avaliada, assim como as tarefas relacionadas à sua construção. Novamente, obtivemos um ótimo resultado com $95 \%$ de avaliações como "Excelente". Já no concernente ao encontro final, às devolutivas das atividades e à pertinência do trabalho final para o curso, mais de $80 \%$ consideraram esses itens excelentes, resultado pouco superior ao alcançado pela "orientação para a realização das tarefas". A única questão abaixo dos $80 \%$ 
foi a referente aos prazos para a elaboração para o trabalho final, aspecto que mereceu a atenção da equipe e foi reformulado para as edições subsequentes.

Tabela 7 - Avaliação Final / Sequência Didática (\%)

\begin{tabular}{lccccc}
\hline \multicolumn{1}{c}{ Item Analisado } & Excelente & Bom & Regular & Ruim \\
\cline { 1 - 2 } Pertinência quanto à proposta do curso & 95 & 5 & 0 & 0 \\
Prazo para a realização das tarefas & 39 & 37 & 24 & 0 \\
Orientação para a realização das tarefas & 79 & 18 & 3 & 0 \\
Devolutiva (feedback) das tarefas & 89 & 11 & 0 & 0 \\
Encontro Presencial Final & 82 & 18 & 0 & 0 \\
\hline
\end{tabular}

Fonte: Apesp, 2013.

Levando em consideração o público-alvo do curso, pedimos que os participantes avaliassem os resultados da oficina na prática/compreensão do trabalho com documentos de Arquivos em sala de aula. Todos os aspectos foram bem avaliados, com quatro deles superando a marca de $90 \%$ de excelência; destes, destacaram-se a contribuição em utilizar fontes diversas em sala de aula e a possibilidade de aplicação dos conhecimentos no trabalho, o que significa que os conteúdos e metodologias desenvolvidos não estão descolados da realidade desses profissionais, sendo possível uma aplicação concreta em sala de aula ou em espaços museológicos, arquivísticos e afins (Primeira oficina EAD..., 2013).

Tabela 8 - Resultados do Curso para os Participantes (\%)

\begin{tabular}{lcccc}
\hline \multicolumn{1}{c}{ Item Analisado } & Excelente & Bom & Regular & Ruim \\
\hline Conhecer as atribuições do Apesp & 89 & 11 & 0 & 0 \\
$\begin{array}{l}\text { Conhecimentos sobre análise de documentos } \\
\text { Utilizar fontes diversas em sala de aula }\end{array}$ & 89 & 11 & 0 & 0 \\
$\begin{array}{l}\text { Possibilidade de aplicação dos conhecimentos } \\
\text { no trabalho }\end{array}$ & 95 & 5 & 0 & 0 \\
$\begin{array}{l}\text { Intenção de aplicar no trabalho o que aprendeu } \\
\text { na oficina }\end{array}$ & 92 & 8 & 0 & 0 \\
$\begin{array}{l}\text { Probabilidade de melhorar seu desempenho } \\
\text { no trabalho }\end{array}$ & 92 & 8 & 0 & 0 \\
\hline
\end{tabular}

Fonte: Apesp, 2013. 
No espaço reservado para que os participantes elencassem de forma discursiva os pontos fortes do curso ou as oportunidades de melhoria, destacaram-se como aspectos positivos a qualidade do corpo docente, as devolutivas (feedbacks) das atividades, além de elogios à bibliografia e ao material de apoio, com algumas menções também à infraestrutura do Apesp e à sua localização. ${ }^{15}$ Quanto às oportunidades de melhoria, foram mencionadas a questão da duração do curso, que inicialmente será elevada em $20 \%$, passando de 50 para 60 horas, e dos prazos para finalização das atividades que, na medida do possível, foram readequados.

\section{CONSIDERAÇÕES FINAIS}

Hoje, quando falamos de políticas públicas que envolvem o universo de instituições arquivísticas, se faz necessário refletir para além da proteção física do patrimônio documental. Ao lado das ações de gestão dos documentos e de preservação - fundamentais para a construção da memória e da história -, assim como da eficiência administrativa, estratégias comprometidas com a difusão do acervo permanente devem ser consideradas atividades primordiais dentro da instituição.

Se concebermos os Arquivos como espaços em diálogo com a sociedade e, em especial, com o público escolar, contribuiremos para a construção de um Arquivo mais democrático. A proposta do curso em EAD, em consonância com as atribuições do Apesp, é uma iniciativa que vai nesse sentido, permitindo que o Arquivo alcance públicos de diferentes regiões do Brasil.

Assim, ao discutir teórica e metodologicamente as fontes documentais dentro da sala de aula, o curso abre espaço para compartilhar experiências em torno da documentação arquivística. Por meio de suas atividades didáticas, promove o debate sobre as diversas possibilidades de trabalho com fontes documentais no âmbito da educação básica, valoriza o papel do professor como produtor do conhecimento e, mais importante, é um instrumento eficaz de difusão do patrimônio histórico-documental.

\section{REFERÊNCIAS}

ALBERCH, Ramón; BOADAS, Joan. La accion pedagogica: el servicio educativo. In: . La funcion cultural de los archivos. Bergara: s.n., 1991. Disponível em: http://www.snae.org/pdf/ikerlanak3.pdf; Acesso em: 10 fev. 2011. 
ALMEIDA, Maria E. B. Desafios e possibilidades da atuação docente on-line. PUCVIVA, São Paulo, n.24, p.73-83, jul.-set. 2005. Disponível em: http://www. apropucsp.org.br/revistas/index; Acesso em: $1^{\circ}$ abr. 2014.

ARQUIVO PÚBLICO DO ESTADO DE SÃO PAULO. Relatório Final do curso EAD "O(s) uso(s) de documentos de arquivo na sala de aula" - 2/2013. São Paulo, 2013.

BARBOSA, Andresa C. O. Arquivo e sociedade: experiências de ação educativa em arquivos brasileiros (1980-2011). Dissertação (Mestrado em História) - Pontifícia Universidade Católica de São Paulo. São Paulo, 2013. Disponível em: http://www. sapientia.pucsp.br/tde_busca/arquivo.php?codArquivo=16282; Acesso em: 15 maio 2014.

BARBOSA, Andresa C. O.; SILVA, Haike R. K. Difusão em arquivos: definição, políticas e implementação de projetos no Arquivo Público do Estado de São Paulo. Acervo: Revista do Arquivo Nacional, Rio de Janeiro, v.25, n.1, p.45-66, jan.-jun. 2012.

BELLOTTO, Heloisa L. Arquivos permanentes: tratamento documental. Rio de Janeiro: Ed. FGV, 2007.

BRASIL. Ministério da Educação. Edital no 01, de 8 de maio de 2013. Exame Nacional do Ensino Médio - Enem 2013. Disponível em: http://download.inep.gov.br/ educacao_basica/enem/edital/2013/edital-enem-2013.pdf; Acesso em: 7 abr. 2014. (Anexo II - Matriz de Referência).

BRASIL. Presidência da República. Constituição da República Federativa do Brasil de 1988. Governo Federal, 5 de outubro de 1988. Disponível em: http://www. planalto.gov.br/ccivil_03/constituicao/constituicao.htm; Acesso em: 12 dez. 2012.

BRASIL. Presidência da República. Lei no 8.159. Dispõe sobre a política nacional de arquivos públicos e privados e dá outras providências. Brasília, 8 de janeiro de 1991. Disponível em: http://www.planalto.gov.br/ccivil_03/leis/L8159.htm; Acesso em: 18 jan. 2013.

CAIMI, Flávia E. Fontes históricas na sala de aula: uma possibilidade de produção do conhecimento escolar? Anos 90, Porto Alegre, v.15, n.28, p.129-150, 2008.

CERRI, Luis F. Ensino de história e concepções historiográficas. Espaço Plural, ano X, n.20, p.149-154, 2009.

LE GOFF, Jacques. Documento/Monumento. In: História e Memória. Trad. Irene Ferreira, Bernardo Leitão e Suzana Ferreira Borges. 5.ed. Campinas, SP: Ed. Unicamp, 2003.

PAOLI, Maria C. Trabalhadores e Cidadania: experiências do mundo público na história do Brasil moderno. Estudos Avançados, v.3, n.7, p.40-66, 1989. Disponível em: http://www.scielo.br/scielo.php?pid=S0103-40141989000300004\&script=sci_ arttext; Acesso em: 13 fev. 2013.

PRIMEIRA oficina EAD para professores termina bem avaliada por $100 \%$ dos participantes. Arquivo Público do Estado de São Paulo. Notícias, São Paulo, 12 nov. 2013. 
Disponível em: http://www.arquivoestado.sp.gov.br/noticia_ver.php?id=479; Acesso em: 13 dez. 2013.

RIBEIRO, Raphael R.; SANTOS, Alessandra S.; HERMETO, Miriam. A Coleção "Histórias de Bairros de Belo Horizonte": uma ação educativa do Arquivo Público da Cidade de Belo Horizonte. In: OLIVEIRA, Leônidas J. de (Org.) Caderno de Textos - Inverno no MHAB - 2010. Belo Horizonte: Museu Histórico Abílio Barreto, 2010. p.35-47.

ROCHA, Helenice A. B. A escrita como condição para o ensino e a aprendizagem de história. Revista Brasileira de História, São Paulo, v.30, n.60, p.121-142, 2010.

ROCHA, Helenice A. B. Problematizando a organização do ensino de história. In: SEMINÁRIO DE PESQUISA E PRÁTICA EDUCATIVA, 1. Os Desafios da Pesquisa no Ensino de História. Rio de Janeiro, Universidade Federal Rural do Rio de Janeiro, 2009. (Mimeo.)

SÃO PAULO (Estado). Decreto no 54.276, de 27 de abril de 2009. Reorganiza a Unidade do Arquivo Público do Estado, da Casa Civil, e dá providências correlatas. Disponível em: http://www.arquivoestado.sp.gov.br/pdfs/Decreto\%20n.55.276. pdf; Acesso em: 8 mar. 2014.

\section{NOTAS}

${ }^{1}$ As reflexões desse tópico foram elaboradas, com acréscimos e supressões, a partir da dissertação de mestrado de um dos autores deste artigo, desenvolvida com auxílio de bolsa da Coordenação de Aperfeiçoamento de Pessoal de Nível Superior (Capes). Cf. BARBOSA, 2013.

${ }^{2}$ Utilizamos a palavra "Arquivo" grafada com a primeira letra maiúscula quando nos referimos às instituições arquivísticas, e "arquivo" com a primeira letra minúscula quando abordamos conjuntos documentais.

${ }^{3}$ A Constituição de 1988 é a primeira lei na história do Brasil a tratar do acesso, pelos cidadãos, aos documentos produzidos pelas administrações públicas. Também é inovadora, diante das constituições anteriores, ao incumbir à administração pública a gestão de seus documentos e o provimento do seu acesso.

${ }^{4}$ Para saber mais sobre as concepções teóricas acerca do ensino de história, ver: CERRI, 2009.

${ }^{5}$ Nesse sentido, ver: ROCHA, 2010.

${ }^{6}$ As produções finais dos cursistas estão disponíveis em: http://www.arquivoestado.sp.gov. br/difusao/oficina_pedagogica.php.

${ }^{7}$ A elaboração do curso-piloto contou também com a colaboração da servidora Vânia Nelize Ventura.

${ }^{8} \mathrm{O}$ alto número de inscritos das escolas públicas estaduais se explica, em parte, pelo apoio na divulgação que obtivemos da EFAP e da SEE/SP, oriundo da autorização/reconheci- 
mento dela para fins de evolução funcional dos professores, a qual foi concedida pela Portaria da EFAP de 19 ago. 2013 e publicada na página 27 do caderno Executivo I do Diário Oficial do Estado de São Paulo (D.O.E.) do dia 20 ago. 2013. Já a homologação do curso, validando-o de fato para sua utilização na evolução funcional dos professores pertencentes aos quadros dessa secretaria, ocorreu através da Portaria da EFAP de 5 fev. 2014, publicada na página 42 do D.O.E. de 6 fev. 2014.

${ }^{9}$ Inicialmente, estavam previstas setenta vagas. Com o elevado número de inscritos, foram disponibilizadas mais dez vagas. Nesse sentido, se considerássemos apenas o número inicial, a demanda seria de 21,77, um resultado excelente se levarmos em conta tratar-se de um curso com carga horária de 50 horas.

${ }^{10}$ Em virtude de uma parceria entre o Apesp e a Fundação Arquivo e Memória de Santos (FAMS), dois funcionários desta instituição participaram do curso sem que, no entanto, fossem retiradas vagas dos candidatos inscritos em cada um dos perfis supracitados. Foi incluído também um professor da rede estadual que, por problemas técnicos, não teve sua documentação conferida por nossa equipe, de modo que o curso foi iniciado com 83 matriculados.

${ }^{11}$ Alguns candidatos possuíam dupla ou tripla titulação. Para este artigo e para o próprio processo seletivo do curso foi considerada apenas a primeira formação indicada, desprezando-se as segundas ou terceiras graduações. Da mesma forma, a indicação de cursos de pós-graduação lato ou stricto sensu foram ignoradas durante a seleção.

${ }^{12} \mathrm{O}$ percentual de concluintes (53\%) ficou dentro do esperado por nossa equipe. A média de concluintes nas edições anteriores do curso, ocorridas na modalidade presencial, foi de 64\%. Assim, considerando as peculiaridades da modalidade EAD, havíamos projetado, para a primeira edição oferecida ao público externo, algo entre $45 \%$ e $60 \%$ como expectativa de concluintes.

${ }^{13}$ Com a homologação, o curso poderá ser utilizado, também, para a evolução funcional no âmbito da Secretaria Municipal de Educação de São Paulo, contemplando, dessa forma, os professores vinculados a essa rede de ensino.

${ }^{14}$ Esclarecimentos de questões não pedagógicas como dificuldades no uso da plataforma, prazos de entrega do trabalho e dificuldades na postagem das tarefas, somadas ao envio de avisos gerais, foram concebidas como atividades de monitoria, função que foi desempenhada pelo estagiário do NAE, Felipe Landim Ribeiro Mendes.

${ }^{15}$ Tendo em vista que os participantes não residiam na capital, o fato de o Apesp estar localizado ao lado de uma estação da linha Azul do Metrô de São Paulo e, ao mesmo tempo, ao lado de uma rodoviária intermunicipal/interestadual justifica as menções à localização que facilitam o deslocamento daqueles que não conhecem bem a cidade de São Paulo.

Artigo recebido em 30 de maio de 2014. Aprovado em 27 de junho de 2014. 